\title{
CYSTOMETRIC AND PERINEAL ELECTROMYOGRAPHY IN SPINAL CORD-INJURED PATIENTS*
}

\author{
DAVID L. PERLOW, M.D. \\ ANANIAS C. DIOKNO, M.D. \\ From the Section of Urology, Department of Surgery, \\ University of Michigan Medical Center, Ann Arbor, Michigan
}

\begin{abstract}
The results of combined cystometry and perineal electromyography were reviewed retrospectively in 50 consecutive, traumatic spinal cord-injured patients. Early and frequent urodynamic evaluation was found necessary in order to tailor treatment to the changing cystometric and electromyographic states in these patients.
\end{abstract}

The urologic management of patients with spinal cord injury long has been an area of controversy. In the most comprehensive longterm follow-up of the spinal cord-injured patient, renal disease was the main cause of death. ${ }^{1}$ The need to develop an effective management program whose primary goal is preservation of renal function is obvious. This report illustrates the importance of early and frequent urodynamic evaluation in achieving this goal.

\section{Material and Methods}

At this Center the Section of Urology has worked closely with the Department of Physical Medicine and Rehabilitation in the urologic evaluation of spinal cord-injured patients. This report summarizes the cystometric and perineal electromyographic findings in 50 consecutive, traumatic spinal cord-injured patients.

Cystometry was performed using the carbon dioxide $\left(\mathrm{CO}_{2}\right)$ cystometer, and the type of bladder dysfunction was classified according to the original work of Lapides. ${ }^{2,3}$ Electromyography of the periurethral striated muscle was done using the TECA TE-4 electromyograph with 37-mm., Teflon-coated monopolar needles. The specific techniques and classifications used are those as described by Diokno et al. ${ }^{4,5}$

The initial cystometric evaluation of 50 patients with traumatic spinal injury revealed 20

*Resident Essay Prize, Michigan A.U.A., June 1979. spinal shock, 19 reflex, 6 autonomous, 3 motor paralytic, 1 mixed, and 1 uninhibited neurogenic bladders. Initial evaluations were done between two weeks and thirteen years after the time of spinal injury. Twenty-three patients were evaluated at ten weeks or earlier. This group consisted of 12 spinal shock, 5 reflex, 4 autonomous, and 2 motor paralytic neurogenic bladders. Thirty-four patients were evaluated at four months or earlier. This group consisted of 16 spinal shock, 12 reflex, 4 autonomous, and 2 motor paralytic neurogenic bladders.

Of the 20 patients who initially had spinal shock bladders, 7 had later documentation of reflex neurogenic bladders. The average halfway point between the two evaluations was 5.3 months. The longest lasting spinal shock bladders were documented at 4.5 , seven, ten, and thirteen months. These patients had injuries of different spinal levels and severity.

None of the 19 patients who initially presented with reflex neurogenic bladders had subsequent documented cystometric change. The earliest reflex neurogenic bladders were documented at three, four, seven, and ten weeks. These patients also had injuries of different spinal levels and severity. Twentyseven of the original patient group eventually carried the cystometric diagnosis of reflex neurogenic bladder. No patient evaluated after thirteen months with a vertebral $\mathrm{T} 7$ level injury or above had anything but a reflex neurogenic bladder. 
Six patients with autonomous neurogenic bladders, 3 with motor paralytic neurogenic bladders, and 1 with a mixed neurogenic bladhad injuries at verebral T8 level or below.

Forty-nine of the 50-patient study group had electromyography (EMG) of the periurethral striated muscle. At initial evaluation, 19 patients had EMGs in the recovery phase (spinal shock bladder with EMG activity), 8 patients had denervated EMGs, 9 patients had coordinated EMGs, and 13 patients had uncoordinated EMGs. Documented change from uncoordinated to coordinated EMGs occurred in 3 patients. These patients were uncoordinated at three, four and one-half, and five months. On repeat evaluation they were found to have coordinated EMGs at six, twelve, and eight months, respectively. These 3 patients had cervical injuries of different severity. Seven of 8 patients with denervated EMGs were associated with vertebral T8 level injuries or lower.

Of the 19 patients with EMGs in the recovery phase, 7 were later known to change to uncoordinated when reflex neurogenic bladders were documented. None changed to coordinated electromyography.

The final documented EMGs on the 27 patients with reflex neurogenic bladders revealed 8 to be coordinated and 19 to be uncoordinated. The level of injury varied.

\section{Comment}

To maximize renal preservation, accurate knowledge of the specific bladder and sphincter dysfunction is important in the urologic management of the spinal cord-injured patient. Our data reveal that it is impossible to predict either the bladder or sphincter dysfunction at any specific time after injury. The conversion from areflexia (spinal shock bladder) to hyperreflexia (reflex neurogenic bladder) may occur as early as three weeks or as late as thirteen months. We have found also that this transition has no apparent relation to spinal level or severity of injury, and consequently these factors cannot be used as predictive indicators.

For patients evaluated at ten weeks or sooner from the time of injury, 29 per cent had made this transition. For those evaluated at four months or sooner from the time of injury, 43 per cent had made this transition. Generally, this conversion seems most likely to occur between three and six months. This unpredictability makes it important to perform reevaluation every two to three months until the patient's urodynamic and clinical conditions have stabilized.

All cases of documented lower motor neuron bladder dysfunction (autonomous, motor paralytic, or mixed neurogenic bladders) involved injury to the vertebral T8 level or lower. Perineal electromyography in this group revealed denervation 88 per cent of the time.

The electromyographic activity of the periurethral striated muscle was coordinated in 30 per cent ( 8 of 27 ) of the patients with reflex neurogenic bladders. This was not related to level of injury or any other apparent factors. Because uncoordinated EMGs may become coordinated without apparent predictability, it is important always to perform electromyography with cystometrics in these patients.

The cornerstone in preserving renal function in the patients rests with avoiding increased intravesical pressure. Increased intravesical pressure and vesical overdistention have been associated with urinary tract infections, bladder cellules and diverticula, hydroureteronephrosis, renal stones, and consequently, renal deterioration. ${ }^{3,6,7}$ The merit in avoiding increased intravesical pressure is obvious. Because of the changing cystometric and electromyographic findings in these patients, frequent evaluation is necessary to provide proper treatment to meet this end. Such treatment may include pharmacologic manipulations, initiation of intermittent catheterization, ${ }^{8}$ procedures to reduce urethral resistance, or in rare cases, urinary diversion.

Ann Arbor, Michigan 48109 (DR. PERLOW)

\section{References}

1. Hackler RJ: A 25-year prospective mortality study in the spinal cord-injured patient: comparison with the long-term living paraplegic, J. Urol. 117: 486 (1977).

2. Lapides J: Neuromuscular, vesical and ureteral dysfunction, in Campbell MF, and Harrison JH, Eds: Urology, 3rd ed., Philadelphia, W. B. Saunders Co., vol. 2, 1970, p. 1356.

3. Lapides J: Symposium on the neurogenic bladder, Urol. Clin. North Am. 1: 1 (1974).

4. Diokno AC, Koff SA, and Bender LF: Periurethral striated muscle activity in neurogenic bladder dysfunction, J. Urol. 112: 743 (1974).

5. Diokno AC, Koff SA, and Anderson W: Combined cystometry and perineal electromyography in the diagnosis and treatment of neurogenic urinary incontinence, ibid. 115: 161 (1976).

6. Lapides J: Role of hydrostatic pressure and distention in urinary tract infection, in Kass EH, Ed: Progress in Pyelonephritis, Philadelphia, F. A. Davis Co., 1965, p. 578.

7. Koff $\mathrm{SA}$, and Lapides $\mathrm{J}$ : Altered bladder function in staghorn calculus disease, J. Urol. 117: 577 (1977).

8. Lapides J, Diokno AC, Silber SJ, and Lowe BS: Clean intermittent self-catheterization in the treatment of urinary tract disease, Trans. Am. Assoc. Genitourin. Surg. 63: 92 (1971). 